
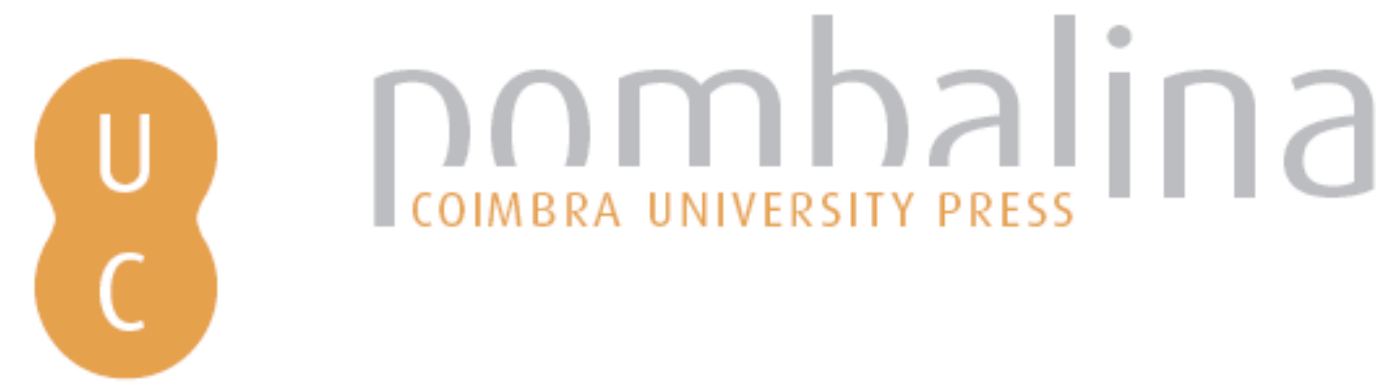

Patrimonio cultural, geografía y turismo: la ciudad como destino de turismo cultural Autor(es): $\quad$ Bertoncello, Rodolfo

Publicado por: Imprensa da Universidade de Coimbra

URL persistente:

URI:http://hdl.handle.net/10316.2/43438

DOI:

DOI:https://doi.org/10.14195/978-989-26-1475-5_9

Accessed : $\quad$ 26-Apr-2023 13:05:15

A navegação consulta e descarregamento dos títulos inseridos nas Bibliotecas Digitais UC Digitalis, UC Pombalina e UC Impactum, pressupõem a aceitação plena e sem reservas dos Termos e Condições de Uso destas Bibliotecas Digitais, disponíveis em https://digitalis.uc.pt/pt-pt/termos.

Conforme exposto nos referidos Termos e Condições de Uso, o descarregamento de títulos de acesso restrito requer uma licença válida de autorização devendo o utilizador aceder ao(s) documento(s) a partir de um endereço de IP da instituição detentora da supramencionada licença.

Ao utilizador é apenas permitido o descarregamento para uso pessoal, pelo que o emprego do(s) título(s) descarregado(s) para outro fim, designadamente comercial, carece de autorização do respetivo autor ou editor da obra.

Na medida em que todas as obras da UC Digitalis se encontram protegidas pelo Código do Direito de Autor e Direitos Conexos e demais legislação aplicável, toda a cópia, parcial ou total, deste documento, nos casos em que é legalmente admitida, deverá conter ou fazer-se acompanhar por este aviso. 


\section{PATRIMONIO CULTURAL, GEOGRAFÍA Y TURISMO: LA CIUDAD COMO DESTINO DE TURISMO CULTURAL}

DOI https://doi.org/10.14195/978-989-26-1475-5_9

RODOLFO BeRTONCELLO ${ }^{67}$

LA PRÁCTICA TURÍSTICA, CAMBIOS Y PERMANENCIAS

Existe hoy un amplio consenso en considerar al turismo como una práctica de gran relevancia. Sin desconocer importantes antecedentes, suele aceptarse el contexto de la Segunda Post-guerra Mundial como un punto de inflexión que instaura un acelerado y permanente crecimiento del turismo, expresado tanto en el volumen de turistas como en la actividad económica asociada al mismo (Vera 1997, Pearce 1986). La consolidación y expansión de las denominadas sociedades de consumo y bienestar, la disponibilidad de mayor tiempo libre y la facilitación de los viajes y traslados de un lugar a otro, han sido señalados como los principales factores que han contribuido a este crecimiento de la práctica y a su difusión entre grupos sociales cada vez más diversos y numerosos (Meethan 2001).

Más allá de este reconocimiento, resulta significativo destacar los estrechos vínculos existentes entre las condiciones sociales y la forma en que se realiza y justifica la práctica turística. Así, en el precitado contexto de expansión del consumo y bienestar que caracterizara a las sociedades desarrolladas durante gran parte de la segunda mitad del siglo XX, el turismo se expresó en modalidades predominantemente masivas orientadas hacia destinos de sol y playa y legitimados por argumentos de restauración de la mano de obra y recompensa por la participación en el mercado de trabajo. Flujos

67. Investigador independiente de CONICET en el Instituto de Geografía de la UBA. Profesor titular del Departamento de Geografía de la UBA. E.mail: bertoncello.rodolfo@gmail.com. 
turísticos masivos y concentrados hacia pocos lugares de destino, han sido la imagen paradigmática de esta modalidad turística.

Ya desde las últimas décadas del siglo XX se reconocen cambios importantes en esta forma de organización de la práctica turística, que continúan hasta la actualidad. La masificación y estandarización de los viajes han sido cuestionados ya sea por las transformaciones en las formas de participación en los mercados laborales (que ponen en tensión las vías de acceso al turismo y su justificación social), como por la consolidación de pautas de consumo que se alejan de estas modalidades para valorar cada vez más la diferenciación y especificación. El crecimiento del turismo deja de depender de la incorporación de nuevos grupos sociales, para ir recayendo cada vez más en la multiplicación de prácticas a lo largo del tiempo (los viajes breves reiterados a lo largo de todo el año compiten cada vez más con las clásicas vacaciones de verano), y del espacio (multiplicando los lugares de destino), en gran medida orientadas a ser realizadas por los mismos individuos. De esta forma, más lugares, más atractivos y más modalidades o formas de realizar turismo, se van incorporando a la práctica, consolidando su tendencia al crecimiento (Meethan 2001, Cohen 2005).

Este crecimiento del turismo, a su vez, se apoya fuertemente en la instauración de condiciones tecnológicas y organizacionales que facilitan el desplazamiento de los turistas desde un lugar a otro. En la medida en que el turismo es una práctica que implica necesariamente un desplazamiento territorial, la consolidación a escala global de redes de todo tipo constituye un sustrato fundamental para este crecimiento, en tanto permiten la circulación de capital, bienes, personas e información de manera más fluida, segura y económica, sin que esta afirmación implique desconocer las marcadas desigualdades que estas redes muestran entre sí y en su despliegue territorial (Bertoncello 2002).

Pero el desplazamiento turístico exige, al mismo tiempo, la existencia de diferencias entre lugares de origen y destino, que motiven y justifiquen el desplazamiento. En efecto, el turista se desplaza desde su lugar de origen buscando satisfacer distintos intereses y objetivos, pero más allá de su diversidad, siempre estará presente el hecho de que esto sólo puede llevarse a cabo o satisfacerse en otro lugar. La precitada diversificación de la práctica turística que hoy se reconoce reside, precisamente, en una sintonía cada vez más fina entre intereses diversos y multiplicidad de ofertas que se orientan a satisfacerlos (Vera 1997). 
De este modo, hoy el turismo se inscribe plenamente en un orden social al que denominamos globalización, en el que conviven tendencias a la homogeneización y a la diferenciación, tanto social como territorial. Al tiempo que las primeras facilitan y promueven la circulación de los turistas entre los puntos más diversos del planeta, las segundas instauran las condiciones que hacen necesaria esta circulación (acceder a otro lugar), al tiempo que también diferencian entre sí a quienes circulan, según sea el lugar al que se dirigen, la modalidad por la que optan o la forma en que realizan su práctica turística (Meethan 2001).

\section{TURISMO CULTURAL, UNA MODALIDAD EN TRANSFORMACIÓN}

El turismo cultural es hoy una modalidad en clara expansión, como lo evidencia la multiplicación de productos y destinos turísticos que se organizan en torno a atributos que, genéricamente y con una notable heterogeneidad, recurren a la cultura como atractivo capaz de concitar la mirada de los turistas (Barreto 2007).

El interés por las manifestaciones culturales no es algo nuevo en el turismo, como lo demuestra el hecho de que entre los primeros viajes organizados de turismo por Thomas Cook a mediados del siglo XIX, se encuentran los que tuvieron como destino las exposiciones universales de París y Londres. El término turismo, inclusive, deriva del nombre que recibía el viaje que jóvenes de la aristocracia y naciente burguesía realizaban ya en el siglo XVIII, para recorrer los lugares de las civilizaciones de la antigüedad, entre ellos Grecia, Roma o Florencia, y que recibía el nombre de Grand Tour, con el fin de completar su educación.

Durante el período de gran crecimiento del turismo en la segunda mitad del siglo XX, el turismo cultural mantuvo su presencia aunque muy por detrás del dominante turismo de sol y playa. Ya fuese realizado en forma individual e independiente (por quienes preferían denominarse viajeros más que turistas, cargando a este último término de una impronta negativa), o ya fuese dentro del formato estandarizado del "paquete turístico", lo cierto es que fue una práctica importante que llevó a grandes contingentes de turistas a lugares paradigmáticos de la cultura universal, donde poder conocer y disfrutar los productos más significativos, valorados fundamentalmente por su carácter de bienes únicos y expresiones excepcionales del genio y labor humanos. 
Estas formas tradicionales de turismo cultural tuvieron dos pilares que resultaron fundamentales para comprender el fenómeno y sus características. Por una parte, se orientaron al conocimiento de atractivos propios de la denominada "alta cultura", a las expresiones del arte y la arquitectura del poder, a aquellos bienes cuyo conocimiento era valorado como parte de una educación integral, cuyo conocimiento ya estaba jerarquizado por los sistemas educativos y era requisito para la inclusión en grupos sociales acomodados, en tanto expresaban valores de pertenencia social y cultural. Por otra parte, el turismo se justificaba en la asunción de que aquello que resultaba atractivo era, al mismo tiempo, auténtico, es decir, era lo que decía ser y lo era de manera unívoca y sin mediaciones. De este modo, la visita al Louvre era, por ejemplo, una práctica obligada para quienes practicaban este tipo de turismo, no sólo porque allí se encontraban las pinturas más significativas de la cultura occidental, sino porque sólo allí se podían observar en sus versiones originales. Las grandes ciudades de Europa, ya fuesen aquellas que atesoraban reliquias de la antigüedad o de la historia cristiana, ya fuesen las que expresaban la magnificencia de las capitales imperiales (como París, Viena o Londres), se contaron entre los destinos más visitados por este tipo de turista.

Estos destinos y atractivos dominantes del turismo cultural fueron siendo paulatinamente complementados por el interés por conocer las expresiones artísticas de otras culturas, interés atravesado en gran medida por el carácter exótico que se asignaba a sus productores. Ya presente entre los primeros viajeros que visitaban Egipto en las últimas décadas del siglo XIX, este interés por las manifestaciones culturales auténticas y únicas se imbricaba fuertemente con el atractivo producido por pueblos y sociedades que resultaban extraños y ajenos, dando lugar a un distanciamiento que permitía definir a "los otros" como atractivos y objetos de interés. Esto último, por cierto, era convenientemente "domesticado" a través de los servicios de hotelería, transporte o guías provistos a la manera occidental, permitiendo de este modo asegurar el mantenimiento de las distancias y, de alguna manera, la sensación de seguridad entre los turistas.

Estas formas dominantes de turismo cultural van a verse fuertemente modificadas a partir de las últimas décadas del siglo XX hasta la actualidad, acompañando las transformaciones ya señaladas en el título precedente, pero mostrando especificidades vinculadas con los cuestionamientos a sus principales pilares de sustentación: el interés por lo auténtico, por las expresiones de la "alta cultura", y por lo exótico y distante. 
Los cuestionamientos a la autenticidad pueden rastrearse en un primer conjunto de advertencias acerca de la "falsificación" de los atractivos y de la propia experiencia, que en gran medida entronca con las críticas al carácter mercantil del turismo (Santana 1997). En efecto, se observa que de la mano de la masificación del turismo se consolidan ofertas donde los atractivos no logran certificar su autenticidad, en tanto suelen ser acondicionados o preparados para su consumo turístico. Esto se denuncia como problemático y se advierte sobre la necesidad de superación, al tiempo que suele culparse a los intereses económicos como los responsables de estas desviaciones. Son, en este sentido, clásicos los reclamos y advertencias acerca de, por ejemplo, los souvenirs de viajes a lugares exóticos, que han sido fabricados en serie en los grandes centros manufactureros.

Sin desconocer lo precedente, otras voces van a cuestionar este carácter "inauténtico" del turismo, poniendo en el eje de la discusión a la experiencia turística, más que a sus atractivos (Mac Cannell 2001, 2003). Desde estas perspectivas, la autenticidad no reposaría en los atributos en sí de los atractivos, sino en la experiencia vivida por los turistas (y por quienes les ofrecen sus servicios), quienes, aún concientes del carácter artificial que podrían tener dichos atractivos, valoran su experiencia como tal. Desde estas lecturas, no tiene sentido advertir acerca del carácter artificial de las danzas con que en Hawai se recibe a los turistas, pues tanto danzarines como turistas saben que participan en una representación de cuyo carácter y objetivos turísticos son concientes. Más allá de posiciones y argumentos, interesa aquí destacar que esta forma de repensar la autenticidad del hecho turístico va a permitir colocar en un lugar destacado a la experiencia turística en sí misma, algo que con el tiempo adquirirá creciente importancia.

A lo anterior se suman también los cuestionamientos a la idea misma de autenticidad y al desdibujamiento de sus valores frente a la copia. En un contexto donde las grandes narrativas son puestas en tela de juicio, y donde la copia pasa a ser multiplicada con perfección técnica hasta niveles insospechados previamente, al tiempo que los originales son reutilizados y puestos en nuevos contextos por la publicidad, las industrias culturales o el diseño, las motivaciones que llevaban a los turistas a querer acceder a esos originales se desdibujan y pierden su carácter perentorio (Meethan 2001) . El cuestionamiento a la autenticidad arrastra también al carácter único y excepcional con que se cargaba al atractivo en el turismo cultural tradicional; si no sólo ya no se puede certificar la autenticidad del atractivo, sino 
que incluso la copia comienza a tener igual valor, entonces ¿qué justifica hacer turismo para acceder a él?

El contexto social y cultural antes señalado, que en términos generales puede designarse como postmoderno, también va a dar lugar a cuestionar el énfasis en los atractivos turísticos expresivos de la alta cultura, para habilitar un creciente interés por otras manifestaciones culturales, que en forma paulatina e impulsado en gran medida por objetivos económicos, va a convertir en atractivos turísticos a un número enorme de expresiones culturales, que se tornan dignas de interés y, como tales, son ofrecidas a los turistas (Barreto 2007). Esto es lo que acontece, en forma notable, con las expresiones de la cultura popular, cuya diversidad y multiplicidad rompe con el monopolio que tenían las raras o "escasas" manifestaciones de la alta cultura que antes atraían a los turistas; fiestas y tradiciones populares o religiosas, hábitos o costumbres, se convierten de este modo en atractivos cada día más convocantes para el turismo. Más aún, el distanciamiento que antes aparecía como requisito necesario para observar "a los otros" se va desdibujando al punto de convertir en atractivas hasta las manifestaciones culturales más próximas al turista, que parece ya interesarse por todo.

De este modo, se llega a una situación como la actual, en la que prácticamente todas las manifestaciones culturales pueden ser, y de hecho muchas de ellas lo son, objeto de interés turístico. Sin importar demasiado ni la autenticidad ni la excepcionalidad, disolviendo distancias y abarcando lo más diverso, el turismo cultural hoy desdibuja fuertemente las diferencias entre lugares y sociedades de origen y de destino, en lo que aparece como una contradicción respecto de esta condición primera de la práctica turística.

Algunos autores han abordado estas cuestiones en el marco del reconocimiento de la existencia de diversos tipos de turistas, señalando que quienes se abocan a las distintas formas de turismo cultural serían individuos convocados por los más diversos atractivos, sin importar sus jerarquías, autenticidad o excepcionalidad. Entre ellos, Cohen (2005) denomina post-turistas a estos individuos interesados más por la ruptura respecto de su cotidianidad $y$, más aún, por la distinción social que el viaje les otorga en sus contextos de origen, que por los atractivos culturales que disfrutan en los lugares a los que se dirigen como turistas. Para éstos, no importa la autenticidad (en tanto reconocen que, en último término, esta no sería más que "un discurso más"), ni los supuestos valores artísticos o históricos presentes, sino la experiencia vivida en su disfrute y durante la estadía. 
Las características que hoy muestra el turismo cultural son, claramente, acordes al contexto social general en el cual la práctica se lleva a cabo. Denominaciones genéricas como la de turismo post-fordista o turismo de nichos aluden a esta condición, en la medida en que permiten reconocer que atributos tales como la multiplicación de atractivos y destinos, asociados a productos turísticos heterogéneos y muy orientados a los gustos y preferencias de consumidores específicos, por ejemplo, replican en esta práctica lo mismo que sucede en el consumo de otros bienes y servicios en las sociedades actuales. El acceso a estos tipos de consumo específicos es, al mismo tiempo, una vía de diferenciación y distinción social en la cual el turismo también participa activamente; en este sentido, la práctica de turismo cultural otorga a quienes la realizan una pátina de jerarquía y distinción frente a quienes "aún" optan por otras ofertas banalizadas como las del turismo de masas de sol y playa, lo que provoca o refuerza nuevas formas de estratificación social vigentes en la actualidad.

LUGARES Y ATRACTIVOS TURÍSTICOS. EL ROL DEL TERRITORIO

Las nuevas formas que adquiere la práctica de turismo cultural en la actualidad otorgan al territorio un papel aún más destacado. Aunque ya se ha señalado que la diferenciación territorial es un componente constitutivo necesario del turismo, esta diferenciación depende cada vez menos de la existencia de atributos que están ya presentes en un lugar y tienen condiciones excepcionales para convertirse en atractivos para los turistas, para ser el resultado de múltiples acciones que promueven esta diferenciación, llevadas a cabo por actores sociales con fines específicos. A modo de ejemplo, cabe señalar que si lo que atrae al turista cultural es la presencia de un atractivo de carácter único como el Coliseo, Roma será el único destino turístico en condiciones de satisfacer este interés; si en cambio lo que atrae la mirada de los turistas son ahora las diversas expresiones de la cultura popular, es evidente que múltiples lugares podrán ser visitados como destinos turísticos en los cuales conocer y disfrutar de estas expresiones. Más aún, si las cualidades intrínsecas de los atractivos turísticos se desdibujan y quedan por detrás de la valoración de la experiencia turística en sí, los potenciales lugares donde realizarla serán más numerosos todavía. Como ya hemos señalado, hoy estas últimas alternativas han cobrado mayor presencia. 
La explosión o "inflación" de lugares de destino turístico a la que se asiste actualmente es, en gran medida, resultado de lo precitado. En la medida en que las motivaciones de los turistas se multiplican y diversifican, se ofrecen productos específicos que responden a cada uno de ellos, en diferentes lugares. El mapa del turismo cultural tradicional, caracterizado por pocos lugares de destino hacia los que convergían masivos flujos de turistas, se ve hoy modificado en tanto se observa que a estos rasgos se suma la multiplicación de nuevos destinos hacia los que se dirigen flujos turísticos menos masivos pero más numerosos y específicos.

Reconocer esta explosión de lugares de destino turístico conlleva la pregunta acerca de cuáles son las condiciones específicas que ellos presentan para convertirse en tales, en la medida en que, si bien las tendencias actuales del turismo cultural habilitan a que muchos lugares puedan ser destinos de turismo cultural, no todos lo son. La respuesta tradicional a esta pregunta ha puesto énfasis en la existencia, en dichos lugares, de atributos que tienen en sí mismos condiciones para convertirse en atractivos y, de este modo, motivar la visita turística; el desarrollo y adecuación de las técnicas de detección, adecuación y gestión de estos atributos ha estado entre los contenidos nucleares de la formación de especialistas en turismo, y ha dado lugar a una voluminosa literatura (Sancho, 1998).

Sin embargo, los lugares no son sólo "contenedores" de atributos potencialmente valorizables para el turismo, sino también ámbitos de intervención de actores sociales concretos que, en su accionar, pueden participar activamente en la selección de algunos lugares frente a otros. Así, por ejemplo, de entre los múltiples lugares donde existen manifestaciones de cultura popular pasibles de convertirse en atractivos turísticos, sólo se convertirán en destinos turísticos aquellos donde estas manifestaciones sean activadas en función de objetivos concretos de quienes intervienen en esto. Esto conduce a que la pregunta precedente requiera, para ser respondida adecuadamente, incluir no sólo la consideración de los atributos preexistentes en el lugar, sino también el análisis de las acciones y actores involucrados en la transformación de un lugar, en lugar de destino turístico. 
Cada lugar de destino del turismo cultural está caracterizado por la presencia de algún atributo que se valora como atractivo. Cuáles son estos atributos y cómo han llegado a ser atractivos son preguntas que encuentran elementos de respuesta en el análisis de las estrategias que diversas investigaciones vienen reconociendo como paradigmáticas, sin que esto implique desconocer las especificidades que adquieren en cada caso.

Una de estas estrategias implica un conjunto de acciones de acondicionamiento del lugar para la definición de sus atractivos y la provisión de condiciones para su disfrute. Mientras todo lugar se caracteriza por poseer una multiplicidad de atributos que le son propios y lo singularizan, sólo algunos de estos rasgos resultan atractivos para el turismo; las acciones de acondicionamiento se orientan, precisamente, a poner en destaque estos rasgos y hacerlos accesibles a los turistas. Se trata de diversas acciones vinculadas con la adecuación material, como por ejemplo la construcción de accesos, lugares de exposición o ámbitos de interacción, que conllevan transformaciones en la configuración espacial de dichos lugares; una presencia muy significativa tienen aquí los procesos de estetización y embellecimiento, en tanto la visión es una función privilegiada en el turismo (Crang 1999, Crouch y Lübbren 2003). Se trata, asimismo, de acciones vinculadas con la construcción de narrativas que orientan la lectura e interpretación de lo que se observa o experimenta, haciendo que "digan" lo que se espera; carteles, guías y folletos suelen ser los instrumentos utilizados para esta construcción, contribuyendo a que los turistas vean sólo aquello que son inducidos a ver (lo que, por cierto, no siempre se logra).

El acondicionamiento del lugar para el turismo involucra, de este modo, su transformación en función de aquello que resulta significativo para el turismo, lo que refuerza su singularidad. Al mismo tiempo, la práctica turística requiere la provisión de un conjunto de servicios y equipamientos para que pueda llevarse a cabo, los que se inscriben en una lógica de homogeneización que en gran medida es contradictoria a la primera. De este modo, el lugar se reinscribe en la tensión entre diferenciación y homogeneización, en función de su rol turístico. De esto deriva la sensación contradictoria que, en muchos casos, atraviesa a los turistas cuando disfrutan de los atractivos de un lugar determinado, al tiempo que utilizan los servicios habituales convenientemente acondicionados para parecer autóctonos. 
Las estrategias de acondicionamiento turístico de los lugares implican una selección y jerarquización de atributos que, evidentemente, no es neutra, en la medida en que establece nuevas diferencias respecto de los individuos y grupos sociales a quienes dichos atributos representan. En el caso del turismo cultural esto suele ser particularmente conflictivo, ya que tratándose de atributos que remiten a identidades y adscripciones sociales, su incorporación a la lógica turística y su adecuación a los fines e intereses turísticos, no siempre coincide con los sentidos o significados que los locales le atribuyen.

Las acciones de acondicionamiento son, también, instancias de intervención de los diferentes actores sociales, que participan en ellas tomando decisiones de acuerdo a sus propios objetivos y expectativas respecto del turismo. Los actores económicos tienen aquí un papel destacado, en la medida en que la oferta turística involucra un conjunto de actividades vinculadas con los negocios; el acondicionamiento turístico, por lo tanto, estará atravesado también por estos intereses. Pero también están presentes intereses políticos, corporativos o sociales diversos, cada uno de ellos interesado en que el lugar turístico resulte funcional a sus objetivos. Las manifestaciones culturales que los turistas observan y disfrutan son el resultado de todo esto.

Otra estrategia muy presente en los procesos de valorización de lugares para el turismo cultural es su tematización. Se entiende por tematización al proceso de construcción de una narrativa específica en torno a un tema, articulada a un conjunto de constructos que, fijos en el territorio, permiten que ese lugar sea asociado con dicho tema, que se torna apelativo para los turistas convocándolos a visitar ese lugar. La tematización suele recurrir a la historia o a hechos del pasado o de la cultura local, que se concretan en un ámbito específico permitiendo que los turistas lo conozcan y vivencien (Boyer 2004; en general Gottdiener 2001). Los relictos materiales vinculados con el tema convocante suelen constituir la base material sobre la que se construye esta estrategia, aunque la misma puede recurrir, en caso de no existir tales relictos, a la réplica y recreación de los mismos, o incluso a la ficción más o menos explícita, como sucede con los denominados "parques temáticos".

La tematización permite, por una parte, otorgar especificidad y relevancia a un lugar, en la medida en que torna visible un rasgo que, de otro modo, sería simplemente uno más de una larga lista que, con el paso del tiempo, los desdibuja y confunde. Es lo que sucede, por ejemplo, en ciudades de América que fueron puerta de entrada de grandes contingentes migratorios, que hoy ofrecen con fines turísticos una tematización de la migración, articu- 
lando hechos históricos con constructos representativos de los mismos, y en los cuales se recrean condiciones para vivencias asociadas al tema.

Por otra parte, la tematización habilita la diferenciación entre lugares que comparten muchos atributos comunes, que sin embargo se asignan sistemáticamente a cada uno de ellos. Ejemplo modélico de esto es la declaración de un lugar como "la capital nacional de..." que estructura un conjunto de atributos y actividades vinculadas con este rasgo, que si bien están ampliamente difundidas en muchos otros lugares, cobran de este modo concreción sólo en este.

Otra de las estrategias es el recurso al patrimonio como atractivo turístico. Si bien la cuestión del patrimonio y los mecanismos que conducen a su activación exceden ampliamente las cuestiones que aquí se abordan, es importante señalar que el uso turístico del patrimonio representa una estrategia de primer orden en la definición de lugares para el turismo cultural, en tanto el mismo constituye un apelativo de gran convocatoria entre los turistas, en especial aquel patrimonio que ha sido instituido como tal por nóminas de prestigio, como sucede con el Patrimonio de la Humanidad de UNESCO (Almirón, Bertoncello y Troncoso 2006).

El uso turístico del patrimonio conlleva una positividad ampliamente aceptada, ya sea porque el turismo contribuye a la valoración y disfrute del mismo, como porque el patrimonio instituido, representa un recurso al que potencialmente recurrir para activar procesos de desarrollo y mejoramiento de la calidad de vida de quienes lo poseen. Sin embargo y más allá de esto, el uso turístico del patrimonio puede conllevar conflictos no sólo por los riesgos para su preservación derivados de este uso, sino también por los problemas que se asocian a las discrepancias que suelen aparecer entre sus dimensiones identitarias (fundamentales para su definición como patrimonio) y los intereses turísticos, sean éstos los de los turistas (que muchas veces los valoran desde otras perspectivas) o los de actores económicos o políticos, que ven en su puesta en valor turístico oportunidades para realizar sus objetivos (Grahm, Ashworth y Tunbridge, 2000).

Para concluir, conviene volver a la caracterización del turismo cultural en la actualidad, en la que se puso en evidencia la multiplicidad de atractivos y lugares de destino, para reconocer la importancia que estas estrategias tienen en los procesos de definición de productos y destinos turísticos. Ellos permiten comprender la transformación -antes aludida- del mapa turístico a escala global. 
Las ciudades son destinos relevantes para el turismo cultural, algo que en absoluto es novedoso; en efecto, ciudades como Roma, París o El Cairo son destinos del turismo cultural privilegiados desde hace largo tiempo, en la medida en que cuentan con acervos artísticos, condiciones históricas o actividades culturales relevantes (Vera, 1997; Pearce, 1986). Sin embargo, y acompañando las precitadas tendencias y transformaciones del turismo cultural, en las últimas décadas se observa la incorporación de un gran número de ciudades que, sin contar con estas condiciones excepcionales, también se han convertido en destinos turísticos. Ofrecen a los turistas un conjunto de atractivos y productos que, si bien son singulares y propios de cada una de ellas, comparten rasgos básicos comunes a muchas, sin con esto perder su condición de interés para los turistas (Judd y Fainstein 1999, Page 1995; Selby 2004).

Los señalamientos presentados al inicio de este capítulo permiten comprender estos cambios desde la óptica de la práctica turística. A ellos deben sumarse los vinculados con las transformaciones que experimentan los propios centros urbanos. En la articulación de ambos conjuntos pueden establecerse las condiciones de posibilidad para el actual desarrollo del turismo cultural en las ciudades.

En relación a estas transformaciones urbanas, puede decirse aquí, en forma sintética, que ellas se inscriben en tendencias estructurales que han afectado sus roles y funciones tradicionales, en el contexto de la profunda reconfiguración en los órdenes más diversos asociada a las denominadas sociedades postindustriales o capitalistas avanzadas (Jameson 1995, Harvey 1998). La búsqueda de nuevas funciones que permitieran superar los contextos de crisis y decadencia detectados, ha sido el común denominador de un conjunto de medidas que, muchas veces encuadradas en prácticas y discursos vinculados con la planificación estratégica y el city-marketing, han buscado dotar a las ciudades decadentes de nuevas condiciones que contribuyeran a superar este contexto negativo (Smith, 1996). En el marco de la intensa competencia y homogeneización de las tendencias dominantes en el contexto global, estas medidas y apuestas han procurado reposicionar a cada ciudad en un lugar destacado recurriendo, en gran medida, a la valorización de sus especificidades. La prioridad dada a los servicios 
en general, y entre ellos a los turísticos, ha sido un núcleo de estas medidas (Britton, 1991).

Necesidades a ser superadas derivadas de situaciones de crisis, se suman a las tendencias del turismo cultural para convertir a las ciudades en lugares privilegiados para esta práctica. Las estrategias que se han presentado en el título anterior se reconocen en la mayoría de los denominados casos exitosos de turismo cultural en las ciudades; el recurso al patrimonio, junto con la construcción de íconos y tematizaciones, han estado a la orden del día articulados con procesos de renovación, refuncionalización o rejuvenecimiento (gentrificación), teniendo los casos de ciudades como Bilbao, Baltimore o Barcelona como ejemplos paradigmáticos a imitar (Harvey 1998, Harvey 2002).

En el caso específico de las grandes ciudades, la disponibilidad de complejos entramados culturales vinculados a sus procesos de poblamiento o a sus actividades productivas, a los hechos políticos y sociales que en ellas acontecieron, en gran medida materializados en sus construcciones y monumentos, sus barrios y sus lugares cargados de significados, contribuyen en la producción de ofertas de turismo cultural que recurren a ellos como si fuesen materias primas seleccionadas y acondicionadas para su consumo turístico. Ejemplo paradigmático de esto es lo que sucede con los antiguos equipamientos portuarios, presentes en muchas de estas ciudades e igual de obsoletos debido a las imposiciones del cambio tecnológico, son objetos de intervenciones que al tiempo que los restauran les otorgan nuevas funciones, los ponen a disposición de nuevos residentes y los acondicionan con criterios estéticos que mezclan lo específico de cada caso con elementos de homogeneidad, transformándolos de este modo en objetos para el consumo turístico, ya sea como atractivos a ser vistos y conocidos, ya como ámbitos propicios para la consumación de una experiencia turística que, en muchos casos, consiste en estar y recorrer, en observar a los demás turistas y habitantes, o en hacer lo mismo que ellos.

Los procesos de patrimonialización juegan un papel fundamental en estos productos y lugares para el turismo, en tanto legitiman mediante criterios expertos los procesos de selección y preservación de partes de una totalidad indiferenciada, que se tornan identificables y luminosas a partir de su inclusión en elencos patrimoniales (y su consecuente separación de esa totalidad indiferenciada), convirtiéndose así en atractivos turísticos muchas 
veces tematizados recurriendo a los mismos argumentos que justificaron la patrimonialización.

Las diferencias y diversidades propias de toda metrópoli, expresadas en sus barrios y sus funciones, en sus costumbres e idiosincrasia, también proveen elementos para el consumo del turismo cultural. La pobreza y la opulencia integran la oferta de atractivos propios de los villa o favela tours como de los city tours, espectáculos del circuito internacional o festivales barriales son incluídos en guías y páginas web de turismo y ofrecidos a los visitantes. La tematización de la ciudad en función de sus historias y su literatura, de sus leyendas o su vida cotidiana, permiten la multiplicación de atractivos y experiencias enriquecedoras para quienes la visitan. Las ciudades se convierten, de esta manera, en lugares privilegiados por las nuevas tendencias del turismo cultural.

Estas tendencias se observan claramente también en diversas ciudades de la Argentina, donde en el contexto de una explícita apuesta al turismo, ${ }^{68}$ primero en la ciudad de Buenos Aires y luego y en forma paulatina en distintos centros urbanos del interior, se puede observar cómo el turismo se instala como una práctica presente y una actividad que genera expectativas de crecimiento económico y desarrollo.

El caso de la ciudad de Buenos Aires es paradigmático en este sentido, en tanto ha visto un notable crecimiento del turismo, particularmente a partir de inicios del siglo XX. Hoy la ciudad ofrece a los turistas un conjunto de atractivos que coinciden con los valorados por el turismo cultural actual; la intrincada y compleja coexistencia de rasgos de homogeneidad globalizada junto a otros peculiares y propios, se encuentra en el núcleo de su atractividad turística. Ellos resultan, en parte, de la complejidad de la vida cotidiana de la gran ciudad y, en parte, son el resultado de diversas políticas públicas que se orientaron a la revitalización económica, el rescate patrimonial o la legitimación política. Ejemplos de esto son las medidas de preservación y acondicionamiento tomadas en el Centro y barrio de San Telmo, el acondicionamiento del sector de Caminito y Vuelta de Rocha en el barrio de La Boca, la refuncionalización de Puerto Madero o la tematización del barrio

68. La que se evidencia, por ejemplo, en la promulgación de la Ley Nacional de Turismo № 25.997, la formulación e implementación del Plan Federal Estratégico de Turismo Sustentable (PFETS) por la Secretaría de Turismo de Nación en 2005, o la jerarquización al rango de Ministerio de esta última. 
de La Recoleta como emblema de la ciudad europea y cosmopolita (Bertoncello y Troncoso, 2013).

La ciudad convertida en un escenario para ser mirado y admirado por los turistas va incluyendo cada vez más fragmentos de su totalidad cotidiana, garantizando la oferta de nuevos productos y el mantenimiento de su atractividad. Pero este escenario que se disfruta mediante su visita y recorrido, es también un lugar donde los turistas realizan prácticas próximas a su cotidianeidad pero que se especifican y distinguen, precisamente, por el ámbito donde ellas ocurren, convenientemente embellecido y tematizado. La ciudad también ofrece su propia cotidianeidad al consumo de los turistas, quienes valoran esta posibilidad de realizar actividades que reconocen como propias de las ciudades modernas y pujantes, pero que se llevan a cabo en contextos singulares y específicos de esta ciudad. Muestra de esto es la amplia aceptación de la oferta de servicios culturales o gastronómicos, muchos de ellos inscriptos en una matriz patrimonial, de los que hacen uso los turistas que visitan la ciudad.

Otras ciudades se han ido incorporando a esta oferta de turismo cultural, a partir de la activación de sus especificidades y la organización de la oferta de servicios turísticos concomitante. Pueden citarse, sólo como ejemplos, la apuesta al rescate patrimonial realizada en la ciudad de Córdoba, que se consolida con la declaración de la Manzana y Estancias Jesuíticas como Patrimonio de la Humanidad por UNESCO, o la que se ha llevado a cabo en la ciudad de Salta a partir del acondicionamiento y tematización de su centro histórico vinculado al pasado colonial.

\section{CONCLUSIONES}

Lejos en el pasado parecen haber quedado las propuestas de turismo cultural concentradas en unos pocos atractivos vinculados a la alta cultura, y a los pocos lugares de destino donde estos se encontraban. Hoy el turismo cultural muestra su interés por las expresiones culturales más diversas, y las encuentra en una multiplicidad de lugares. Como resultado de esto, puede decirse que el turismo cultural integra en plenitud las redes del turismo global actual.

Este turismo global se sostiene por la existencia de redes que articulan lugares de manera eficiente y los integran bajo un manto de homogeneización. 
Los sistemas de transporte y comunicación, de gestión de servicios de todo tipo, dan soporte al desplazamiento de personas, bienes, capital o información, que hacen posible la práctica turística, permitiendo viajes y desplazamientos para el disfrute de todo aquello que la motiva.

Pero al mismo tiempo en que acontece esta integración y homogeneización, el turismo requiere de la recreación constante de diferencias y singularidades que, cargadas de maneras desiguales en los distintos lugares, sostengan la motivación del viaje, esto es, conocer lo diferente. El turismo cultural tal como hoy se lo practica juega un papel fundamental, en la medida en que habilita la reproducción amplia y constante de estas diferencias en múltiples lugares. La imagen de una totalidad que se sustenta en la coexistencia de homogeneidad y diferenciación es, sin dudas, potente para comprender el turismo cultural en la actualidad.

La relevancia que el turismo muestra en la actualidad se expresa en la expansión y dinámica que acaba de caracterizarse, además de su manifestación en cifras de viajeros o flujos de inversión, ganancias o intercambios económicos. Interesa aquí destacar que esta relevancia es también evidencia del rol que el turismo ocupa en los procesos sociales generales, en los que participa y a los que contribuye a consolidar. Ya sea que se ponga énfasis en su condición de instancia de estímulo al consumo o de la redistribución de riquezas, a la incentivación de nuevas pautas de diferenciación y distinción social, o de legitimación de determinadas estructuras de poder o matrices culturales, lo cierto es que el turismo requiere, para su adecuada comprensión, que se lo analice en relación a todas estas cuestiones, superando las perspectivas que lo consideran en sí y en forma aislada del resto de las dimensiones sociales. Requiere, al mismo tiempo, que se superen los prejuicios respecto a esta práctica, que han limitado en muchas ocasiones, su estudio desde perspectivas interpretativas más significativas.

Evidencia de esto puede reconocerse en la forma en que son analizados los atractivos y lugares del turismo cultural. Las nuevas manifestaciones de esta modalidad tornan perentorio superar los análisis enfocados en la descripción de atractivos presentes en cada lugar, como si ellos fuesen atributos inherentes de dichos lugares, para indagar en los procesos concretos que llevan a que determinados rasgos de algunos lugares se conviertan en turísticos. ¿Cómo y porqué?, ¿quiénes o cuándo?, son preguntas cuyas respuestas requieren de investigaciones que, al tiempo que produzcan evidencias sobre el hecho analizado, se inscriban en matrices conceptuales fértiles 
para su adecuada interpretación. Se espera que este capítulo contribuya en este sentido, aportando ideas y reflexiones que inviten a seguir transitando este camino.

\section{REFERENCIAS BIBLIOGRÁFICAS}

ALMIRÓN, Analía, R. Bertoncello y C. Troncoso. 2006. “Turismo, patrimonio y territorio. Una discusión de sus relaciones a partir de casos de Argentina", Estudios y Perspectivas en Turismo 15(2), 101-124.

BARRETTO, Margarita. 2007. Turismo y cultura. Relaciones, contradicciones $y$ expectativas (Tenerife: ACA y Pasos).

BERTONCELLO, Rodolfo y Claudia Troncoso. 2013. "La ciudad como objeto de deseo turístico. Buenos Aires y Salta como destinos turísticos", Actas de las XI Jornadas Cuyanas de Geografía y IV Congreso Nacional de Geografía de las Universidades Públicas (Mendoza: Universidad Nacional de Cuyo), s.p.

BERTONCELLO, Rodolfo. 2002. "Turismo y territorio. Otras prácticas, otras miradas". Aportes y transferencias 6(2), 29-50.

BOYER, M. C. 2004. "Ciudades en venta: la comercialización de la historia en el South Street Seaport", en M. Sorkin (ed.) Variaciones sobre un Parque Temático. La nueva ciudad americana y el fin del espacio público(Barcelona: Gustavo Gili), 205-230.

BRITTON, Stephen. 1991. “Tourism, capital, and place: towards a critical geography of tourism", Environment and Planning, D Society and Space 9, 451-478.

COHEN, Erik. 2005. "Principales tendencias en el turismo contemporáneo", Política y Sociedad, 42(1), 11-24.

CRANG, Mike. 1999. "Knowing, tourism and practices of vision", en Crouch, David (ed.) Leisure/tourism geographies. Practices and geographical knowledge (London: Routledge), 238-256.

CROUCH, David y Nina Lübbren. 2003. Visual cultural and tourism (New Cork: Berg Publishers).

GOTTDIENER, M. 2001. The Theming of America. American dreams, media fantasies and themed environments (Oxford: Westview). 
GRAHAM, B., G. Ashworth and J. E. Tunbridge. 2000. A Geography of heritage. Power, culture and economy (London: Arnold Publishers).

HARVEY, David. 1998. La condición de la posmodernidad. Investigación sobre los orígenes del cambio cultural (Buenos Aires: Amorrortu).

HARVEY, David. 2002. "The art of rent: globalization, monopoly and the commodification of culture", Socialist Register, 38, s.p.

JAMESON, Frederic. 1995. El posmodernismo o la lógica cultural del capitalismo avanzado (Barcelona: Paidos).

JUDD, D. y S. Fainstein. 1999. The Tourist City (New York: Yale University Press).

MAC CANNELL, Dean. 2001. “Tourist Agency”, Tourist Studies. 1(1), 23-37.

MAC CANNELL, Dean. 2003 [1976]. El turista. Una nueva teoría de la clase ociosa (Barcelona: Melusina).

MEETHAN, Kevin. 2001. Tourism in global society. Place, culture, consumption (New York: Palgrave).

PAGE, Stephen. 1995. Urban tourism (New York: Routledge).

PEARCE, Douglas. 1986. Tourist development (New York: Longman).

SANCHO, Amparo (dir.). 1998. Introducción al turismo (Madrid: OMT, Organización Mundial del Turismo).

SANTANA, Agustín. 1997. Antropología y turismo. Nuevas hordas, viejas culturas? (Barcelona: Ariel).

SELBY, Martin. 2004. "Consuming the city: conceptualising and researching urban tourist knowledge”, Tourism Geographies 6(2), 186-207.

SMITH, Neil. 1996. "Gentrification, the frontier and the restructuring of urban space”, en S. Fainstein \& Scott Campbell (eds), Readings in Urban Theory (Oxford: Blackwell Publishers), 338-358.

VERA, J. Fernando et al. 1997. Análisis territorial del turismo (Barcelona, Ariel). 